\title{
Optimized designing of PID controller for variable speed wind turbine systems using PSO algorithm
}

\author{
Somayeh Abdolzadeh ${ }^{1}$, Seyed Mohammad Ali Mohammadi ${ }^{2}$ \\ ${ }^{1}$ M.Sc. Student of Islamic Azad University, Science and Research Branch of Sirjan \\ ${ }^{2}$ Assistant Professor of Shahid Bahonar University of Kerman
}

\begin{abstract}
The PID controller design is a very popular method for controlling industrial processes and due to its simple structure and effective operation; it is used in a wide range of industries. In this paper, a method is provided for setting up the PID controller and Particle swarm optimization (PSO) algorithm is used to design a variable speed wind turbine system. The provided method has advantages such as easy implementation, stable convergence characteristics and high performance in computing. Finally the results are displayed.
\end{abstract}

Keywords: variable speed wind turbine, the blade control, fuzzy controller, the controller PID 


\section{Introduction}

According to the forecasts, it is expected that by 2050 global demand for energy grows up to 3 times. At least 15 to 20 percent of global energy demand will be met directly by new and renewable energy sources [1]. In the year 2011, compared to the end of 2009, the rapid growth of $50.532 \%$ can be seen in the volume of energy intake (MW) of wind turbines in the world that the current leaders of the movement are advanced industrial countries [2]. The use of Wind energy is on the rise because it is clean, but the truth about wind power is that wind energy is expensive and for economic use, it is necessary to minimize the occurrence of errors in it [3]. The first wind turbines connected to the power network was built on the Orkney Islands in Great Britain in 1951 [4]. Production of nuclear and fossil power and other energies which are harmful for the environment, peace and human welfare, must be replaced with better methods, it means that they should turn into the form of available renewable energy in the environment [5]. One of the factors which causes tensions and amortization in wind turbines is fluctuations and high overshoot. Because the axis of the wind turbine generator is coupled with the generator shaft, the speed fluctuations will transfer to the generator so the amortization of generator and wind turbine will increase. For this reason, preventive care and maintenance for the turbines increases. Due to the high cost of wind turbines and setting up them in difficult access regions, such a large depreciation will involve high costs, which shows the importance of the speed control of wind turbines. If you do not control the wind turbine fluctuations, fluctuations in electrical frequency can be seen in the induction generators, so with less money, the speed of the wind turbine can be controlled to a large extent. So in this article, after the introduction of wind turbines and their linear model, three types of controller consist of fuzzy, PID and adaptive fuzzy PID to control the speed and overshoot of the wind turbine will be introduced. The results of its simulation are shown using Simulink / Matlab software. The results showed that adaptive fuzzy PID controller has provided a good and effective performance for system response. The paper consists of 6 parts; the first part is an introduction to wind energy, the second part introduces wind turbine, the third part introduces the dynamic relationship of wind turbine, in the fourth part operator model and wind turbine controllers are discussed, in the fifth part simulation and final part VI is the conclusion.

\section{The introduction of wind turbines}

In most wind turbine, rotor and wind turbine generator are the main control method and general model of Figure 1 can be considered to understand the relationship of controllers with the other components of the wind turbine system.

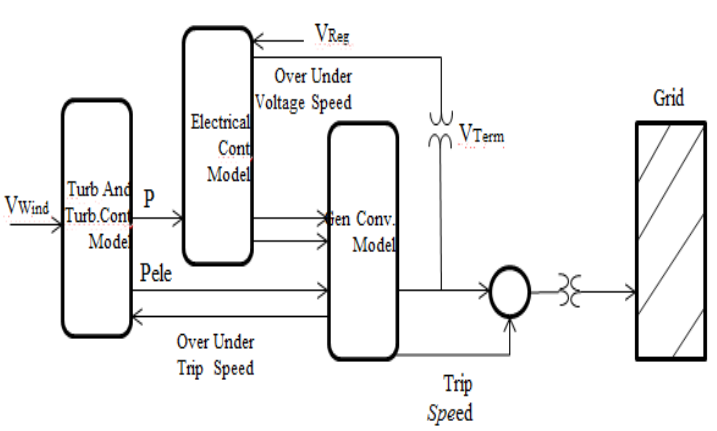

Figure 1: The general model of wind turbines and their interactions

The general model of a wind turbine includes a generator / converter model which is located between wind turbine generator (WTG) and grid and it is used to convert mechanical power to electrical power and to determine the rotor speed. This model also includes a wind turbine as an electromechanical system for converting the kinetic energy of wind into electricity. It is a simple example of a very complex electromechanical system. The model shows the active and reactive power which is transferred to the power system based on input from the turbine model and condition of the power system [6]. In the model shown in Figure 2, wind speed model can be used for generating a wind 
signal that can be applied to the rotor, rotor model is used to convert the kinetic energy contained in the wind to the mechanical power can be applied to the generator; The rotor speed controller is used for deriving a power set point from the rotor speed versus generator power control characteristic, based on the actual rotor speed; pitch angle controller is used for changing the blade pitch above nominal wind speed preventing the rotor speed from becoming too high; voltage controller is used for keeping the terminal voltage near its reference value; protection system is used for limiting the converter current and for switching off the wind turbine when terminal voltage or grid frequency deviation exceed a specified value for a given time. In Fig. 2, the turbine model and its controllers is depicted.

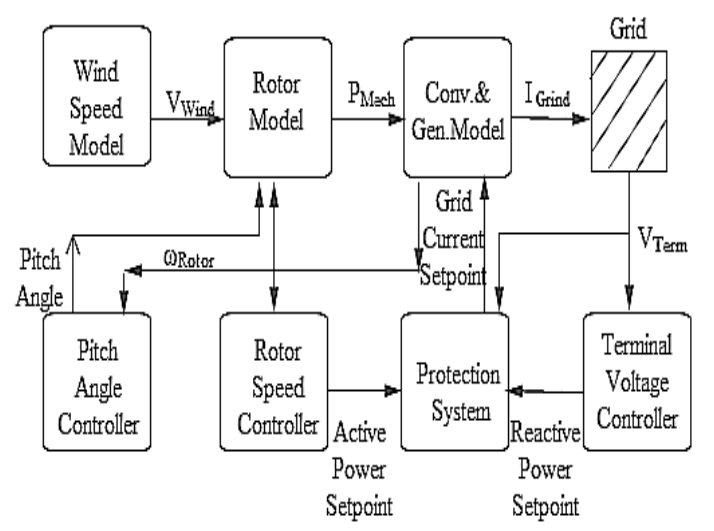

Figure. 2: the turbine model and its controllers

\section{The relationships of the dynamic model of wind turbine}

The main dynamics of the variable speed wind turbine are obtained by the following mathematical model:

$$
\begin{gathered}
J_{t} \omega_{t}=T_{w}-T_{m} \\
J_{t}=\rho_{\mathrm{a}} \cdot I
\end{gathered}
$$

Where $\mathrm{J}_{\mathrm{t}}$ is the moment of inertia of the turbine rotor which is obtained from the equation (2), I is the moment of inertia, $\mathrm{Qa}_{\mathrm{a}}$ is regional density of the rotor axis, which is obtained by multiplying the length in the bulk density [7], $\mathrm{W}_{\mathrm{t}}$ is Angular velocity of turbine axis, $\mathrm{T}_{\mathrm{m}}$ is the necessary mechanical torque to turn the generator, and it is obtained by the equation (3) [8]:

$$
\mathrm{T}_{\mathrm{m}}=\frac{\rho \mathrm{ARC}_{T} V_{W}^{2}}{2}
$$

Where $\varrho$ is air density, A is the area swept by the blades and $\mathrm{C}_{\mathrm{T}}$ is torque coefficient, which obtained by the following equation $C_{T}=C_{p} / \lambda$ where $\lambda$ is the ratio of the velocity of at the tip of the blades and it is the ratio of the angular velocity of the rotor to the linear wind speed at the tip of the blades $\left(\lambda=\frac{\omega_{t} R}{V_{w}}\right), \mathrm{R}$ is the radius of the wind turbine rotor and $V_{w}$ is the wind speed.

The wind turbine is determined by the power coefficient curve $\left(C_{p}\right)$ as a function of the speed of the blade tip $\lambda$ and pitch angle ( $\beta$ or $\theta$ ). The nonlinear dynamic model of turbines around the operating point is converted to the linear form of the following equation [8]:

$$
J_{t} \Delta \omega_{t}=\gamma \Delta \omega_{t}+\zeta \Delta V_{W}+\delta \Delta \beta
$$

Where $\zeta, \delta$, and $\gamma$ are linearization coefficients and here $\Delta \mathrm{V}_{\mathrm{w}} \Delta \omega, \Delta \beta$ represents a deviation from the operating point of $\mathrm{V}_{\text {wop }}, \beta_{\mathrm{oP}}, \mathrm{W}_{\text {top. }}$. Selecting an operating point is important for maintaining the aerodynamic stability in the system. Establishment of the blade, $\omega$ and wind speed are fixed values which are selected suitably for turbine, then using the Laplace transform function, the equation is obtained as follows:

$J_{t} s \Delta \omega_{t}=\Upsilon \Delta \omega_{t}+\xi \Delta V_{W}(s)+\delta \Delta U(s)$

The speed of the turbine rotor axis is equal to:

$\Delta \omega_{t}=\left[\frac{\xi}{J t} \Delta \mathrm{V}_{W}(s)+\frac{\delta}{J t} \Delta \mathrm{U}(\mathrm{s})\right] \cdot \frac{1}{S-D}$

Equation (6) represents the linearized model of a wind turbine, a block diagram of this model is shown in Figure 3 [8]. 


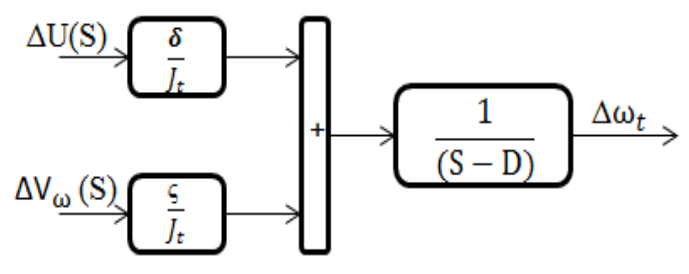

Figure 3: a block diagram of the linearized model of a wind turbine

\section{Operator model and wind turbine controller}

Here the control of input speed to self-stimulate, induction generator that moves by the wind turbine, is done through the control of wind turbine components. For this purpose, the linearized dynamics model of the wind turbine is used. The PID controller is used to control the speed of the turbine rotor, in practice, to do this, in addition to the PID controllers, the operator also must be adjusted until turbine blades placed in the proper position according to the input commands of the operator. the operator can, for example, be a permanent magnet DC motor which is presented in the block diagram of Figure 4, where Ua (s) is the input Laplace and Uo is the output Laplace of the pitch angle, $\mathrm{K}_{\mathrm{m}}$ is the fixed interest $\tau_{\mathrm{m}}$ is the time constant of the permanent magnetic motor [8].

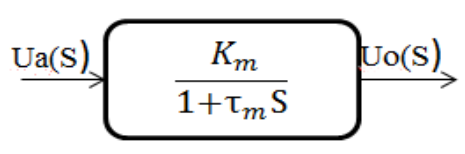

Figure 4. Block diagram of the operator

Speed controller is shown in Figure 5. It is used to control the rotor speed of the wind turbine, where $\Delta \mathrm{W}_{\mathrm{T}}$ (s) is the input speed of rotor (error signal) and $\Delta \mathrm{Uc}(\mathrm{s})$ is the changes in the output pitch angle.

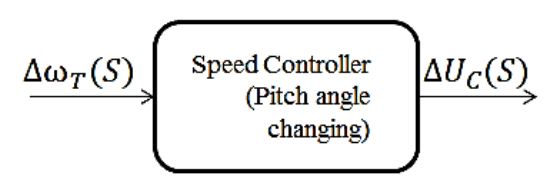

Figure 5. Block diagram of the speed controller
Therefore, if the mentioned models which they are correspond to the controller and operator combined with a dynamic linearized model of the wind turbine, a general model of wind turbine speed controller is obtained as shown in figure $6[6,8]$.

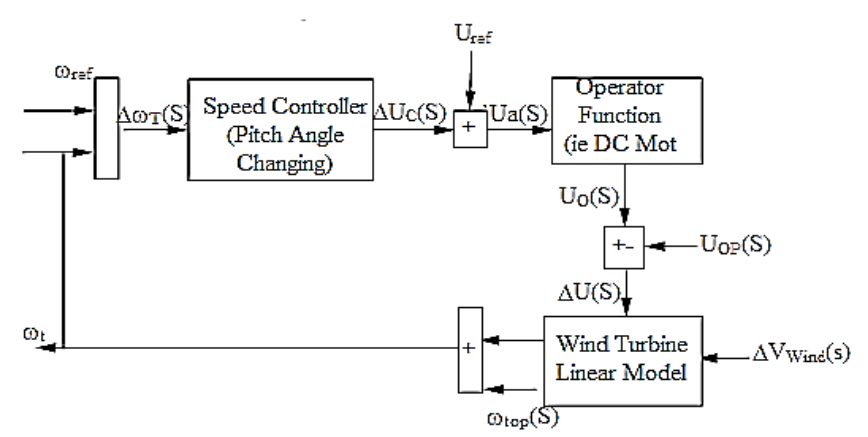

Figure 6. Block diagram of the speed controller system of the wind turbine

\section{Particle swarm optimization (PSO) algorithm}

Particle swarm optimization (PSO) is a population in which a group of particles is searched in a possible space to find the optimal response for an objective function, each component moves with an adjustable velocity in the search space and its best achieved position is kept in its memory and the best position achieved by the entire group is transmitted between all members. In the PSO method members do not upgrade to new members, but their behavior, including position and velocity is modified during the next iterations and a satisfactory solution will eventually be discovered. Let best be the best known position of particle and assume that the search space is an n-dimensional space, then the component $i$ can be defined using two n-dimensional vectors of position $(\mathrm{Xi})$ and velocity (Vi) as following relations:

$\mathrm{X} i=\left[\mathrm{X}_{\mathrm{i} 1}, \mathrm{X}_{\mathrm{i} 2}, \mathrm{X}_{\mathrm{i}}, \ldots ., \mathrm{X}_{\mathrm{in}}\right]^{\mathrm{T}}$

$\mathrm{Vi}=\left[\mathrm{V}_{\mathrm{i} 1}, \mathrm{Vi} 2, \mathrm{Vi} 3, \ldots, \mathrm{Vin}\right]^{\mathrm{T}}$

Where, $\mathrm{i}=1,2,3, \ldots, \mathrm{N}, \mathrm{N}$ is the number of members, and superscript $\mathrm{T}$ is the transpose operator and in the particle swarm optimization (PSO) algorithm. The component $i$ stores its best position ever achieved as the vector $\mathrm{Pi}=[\mathrm{Pi} 1$, Pi2, Pi3, ....., Pin $]^{\mathrm{T}}$ in its memory.Vector $\mathrm{G}=[\mathrm{g} 1$, 
g2, g3, ... ... gn $]^{\mathrm{T}}$ is the best position ever achieved by the entire group and the position of $i^{- \text {th }}$ component in iteration $t+1$ is defined by relations 9 and 10:

$V^{\mathrm{i}}[t+1]=w V^{\mathrm{i}}[t]+c_{1} r_{1}\left(P[t]_{\mathrm{i}}-X_{\mathrm{i}}[t]\right)+$
$c_{2} r_{2}\left(G[t]-X_{\mathrm{i}}[t]\right)$

$X_{\mathrm{i}}[t+1]=X_{\mathrm{i}}[t]+V_{\mathrm{i}}[t+1]$

(10)

In the above equations, $\mathrm{W}$ is inertia coefficient, which reflects the effect of previous velocity vector on the current iteration. $x$ is the coefficient of contraction which is used to limit the impact of velocity vectors, $C_{1}$ and $C_{2}$ are cognitive (or local velocity) and social (or global velocity) parameters respectively, $\mathrm{r}_{1}$ and $\mathrm{r}_{2}$ are two real numbers, which are selected randomly and based on a uniform distribution between zero and one. The greater product of $\mathrm{c}_{1} \times \mathrm{r}_{1}$, the more speed of i-th component, in which it moves towards the best position. The particle speed in which the group is achieved to its best position is also affected by multiplying $\mathrm{c}_{2} \times \mathrm{r}$. The greater inertia coefficient encouraging the group to search within the larger space, while the smaller inertia coefficient, increase the accuracy of group in local search. Based on the gained experience, it is proposed that at the beginning of the search, a large amounts be allocated to $\mathrm{W}$, so a global search has a priority to local search. Then, in order to achieve the best possible results, it gradually changes the small amount such as zero.

\section{Problem Statement and the Objective Function}

PID controller is used to improve the dynamic response of system and to reduce the steady error. The following equation is the PID controller function:

$$
\mathrm{G}_{\mathrm{c}}(\mathrm{s})=\mathrm{K}_{\mathrm{p}}+\frac{K_{\tilde{\mathrm{L}}}}{g}+\mathrm{K}_{\mathrm{d}} \mathrm{S}
$$

$\mathrm{Kp}, \mathrm{Ki}$ and $\mathrm{Kd}$ are the proportional, integral and derivative interests, respectively.The objective function is stated as equation (12):

$\mathrm{F}=\operatorname{sum}(\mathrm{e})^{*}$ beta

The goal is to minimize the area under the curve, $C_{1}$ and $C_{2}$ weight coefficients are equal to 1.2 and 0.12 , respectively, and the amount of 8 and 10 have been considered for the $B$. Range of parameters $\mathrm{Kp}, \mathrm{Ki}$ and $\mathrm{Kd}$ are shown in Table 1.

Table 1. Algorithm parameters

\begin{tabular}{|c|c|c|}
\hline $\mathrm{Kp}$ & 1.07 & 14.09 \\
\hline $\mathrm{Ki}$ & 0.26 & 5.54 \\
\hline $\mathrm{Kd}$ & 0.08 & 6.68 \\
\hline
\end{tabular}

\section{Simulation results}

Set the parameters $\mathrm{Kp}, \mathrm{Ki}$ and $\mathrm{Kd}$ for PID controller leads to changes in the performance of the system closed-loop and therefore create different responses. PID controllers used in the industry have not appropriate setting and thus the performance of the controller is very improvable. Here the particle swarm optimization (PSO) algorithm is used to design the PID controller and to reduce the overshoot and steady-state error.

\section{Designing the PID controller parameters}

Table 2 summarizes the optimal parameters of PID controller designed by particle swarm optimization (PSO) algorithm for 6, 12 and 32 replications. 
Table 2. The results of the PSO algorithm

\begin{tabular}{|c|c|c|c|c|c|}
\hline Method & Iteration & $\mathrm{Kp}$ & $\mathrm{Ki}$ & $\mathrm{Kd}$ & $\mathrm{F}$ \\
\hline PSO & $\mathrm{I}=6, \mathrm{~B}=8$ & 14.09 & 5.54 & 0.10 & $7.1781 \mathrm{e} 3$ \\
\hline PSO & $\mathrm{I}=12, \mathrm{~B}=8$ & 1.74 & 3.72 & 0.47 & 413.5386 \\
\hline PSO & $\mathrm{It}=32, \mathrm{~B}=8$ & 8.15 & 2.43 & 1.68 & $3.5179 \mathrm{e} 3$ \\
\hline PSO & $\mathrm{I}=6, \mathrm{~B}=10$ & 1.07 & 3.99 & 0.89 & 10.7940 \\
\hline PSO & $\mathrm{I}=12, \mathrm{~B}=10$ & 8.97 & 1.90 & 0.12 & 6.5211 \\
\hline PSO & $\mathrm{I}=12, \mathrm{~B}=10$ & 1.78 & 0.26 & 0.08. & 2.7425 \\
& & & & & \\
\hline
\end{tabular}

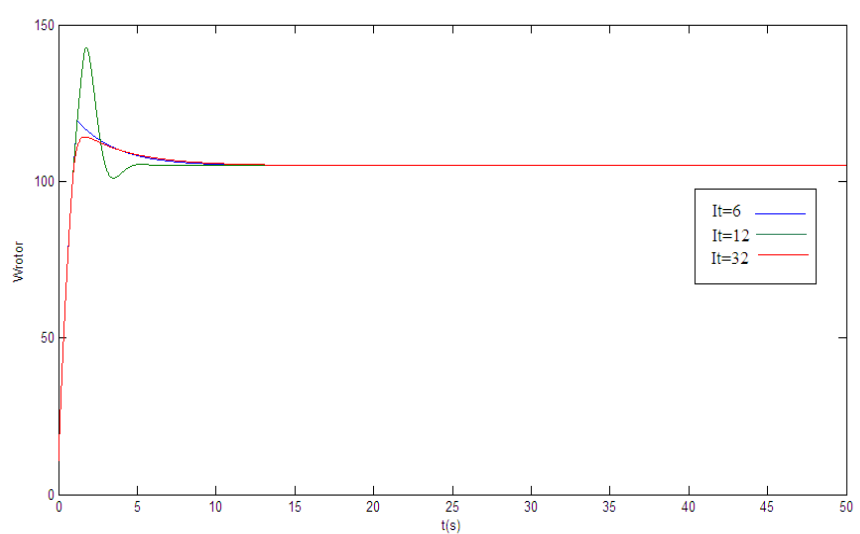

Figure 7. The output speed of the wind turbine rotor after designing the controller $B=8$

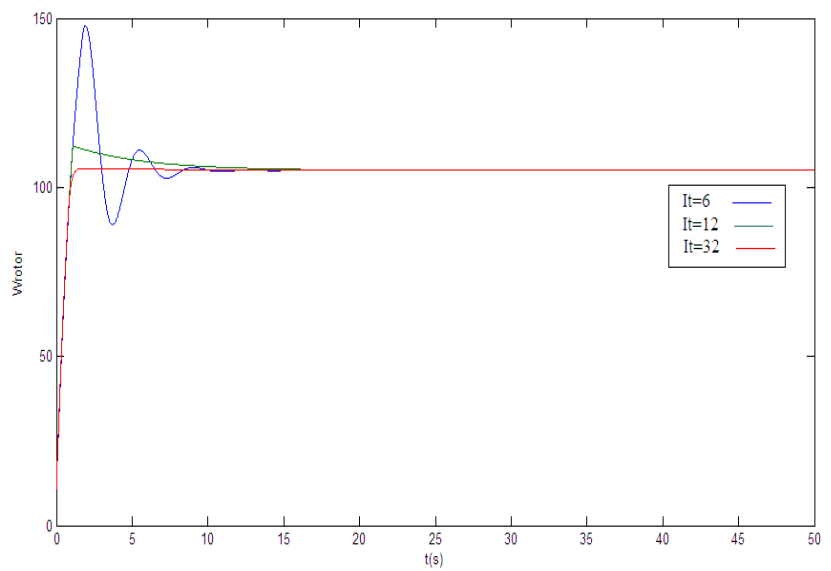

Figure 8 . The output speed of the wind turbine rotor after designing the controller $B=10$ 


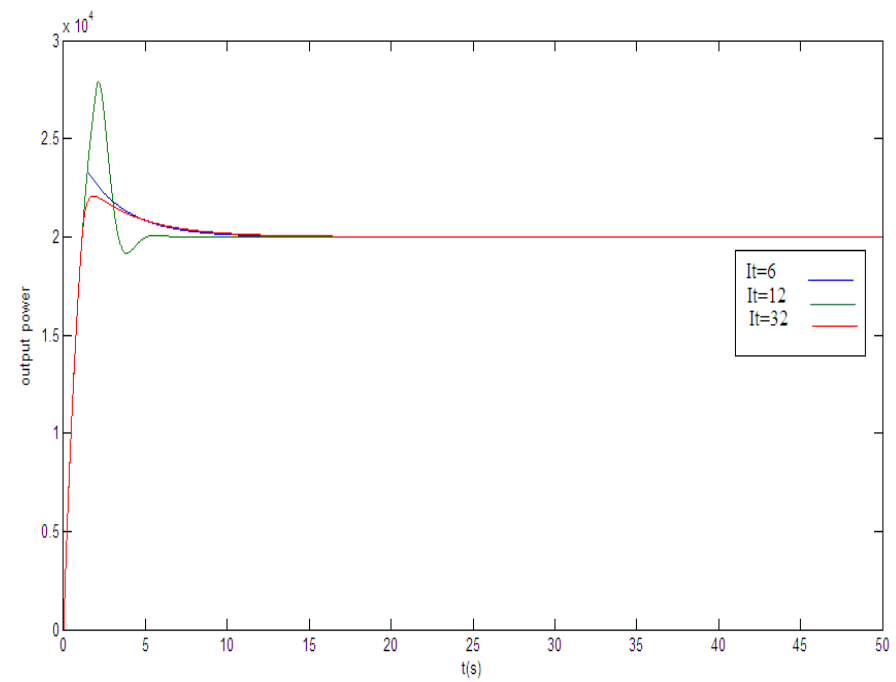

Figure 9. The output power of the wind turbine after designing the controller $B=8$

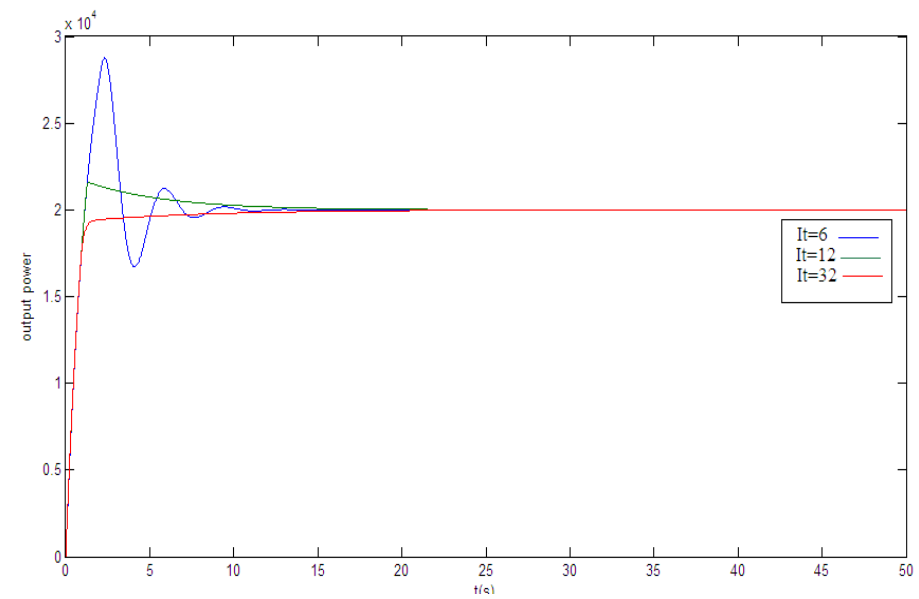

Figure 10. The output power of the wind turbine after designing the controller $\mathrm{B}=10$

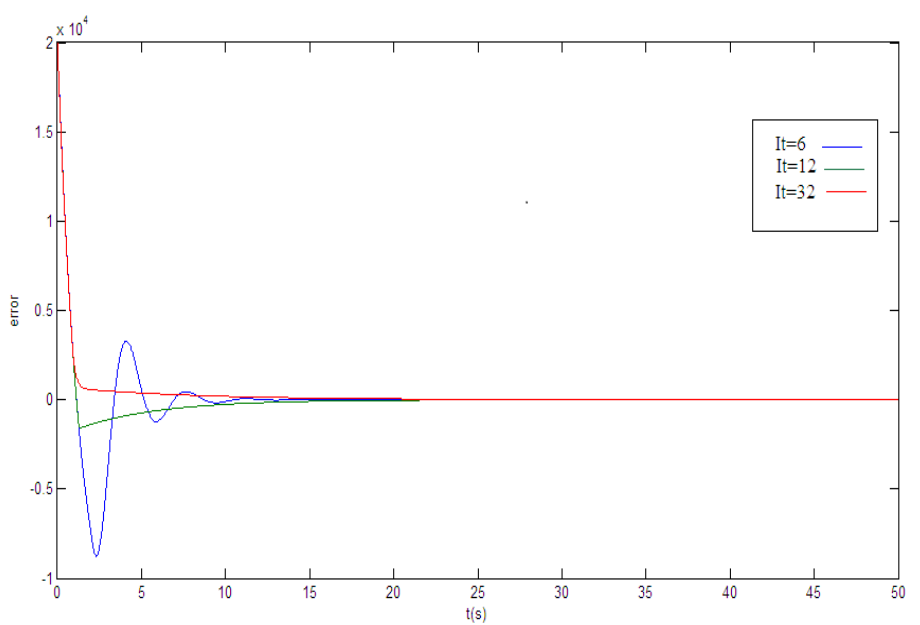




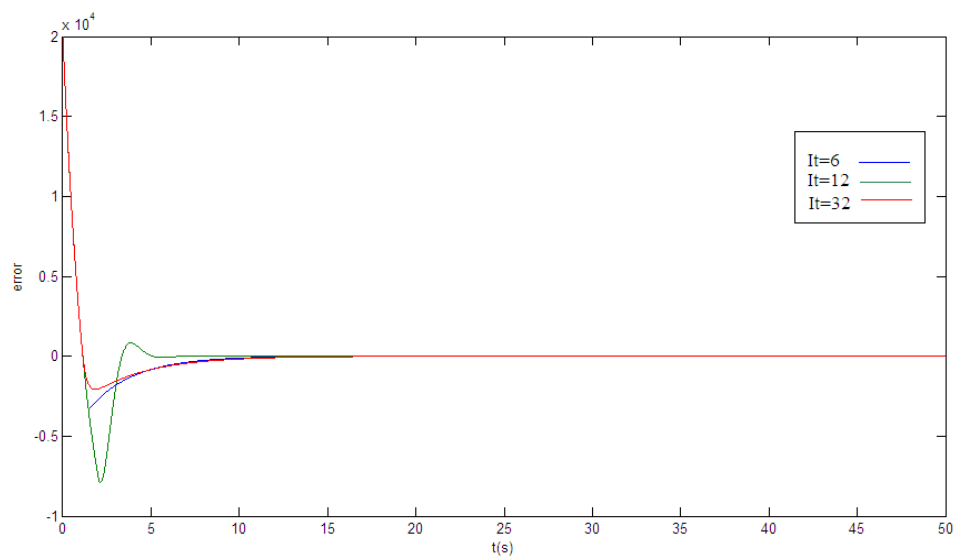

Figure 11. The (power) error of the wind turbine after designing the controller $B=8$

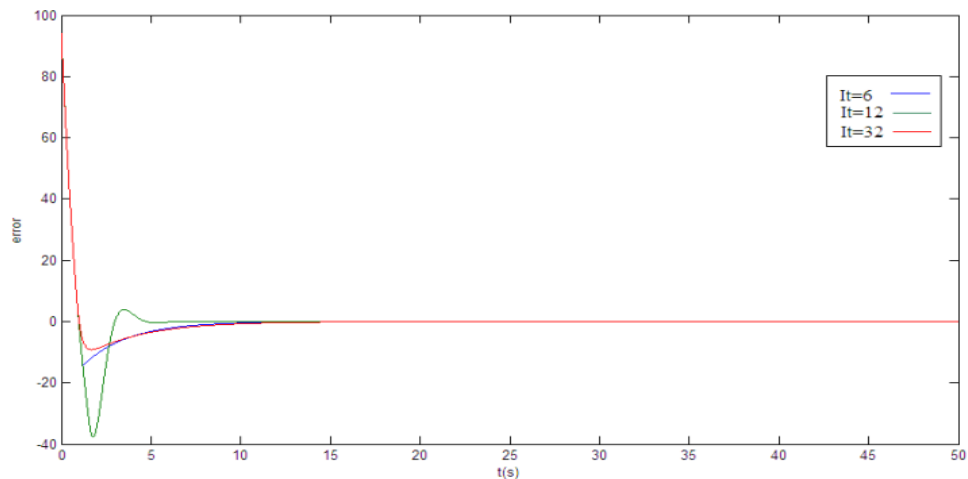

Figure 12. The (power) error of the wind turbine after designing the controller $B=10$

Figure13. The (rotor speed) error of the wind turbine after designing the controller $B=8$

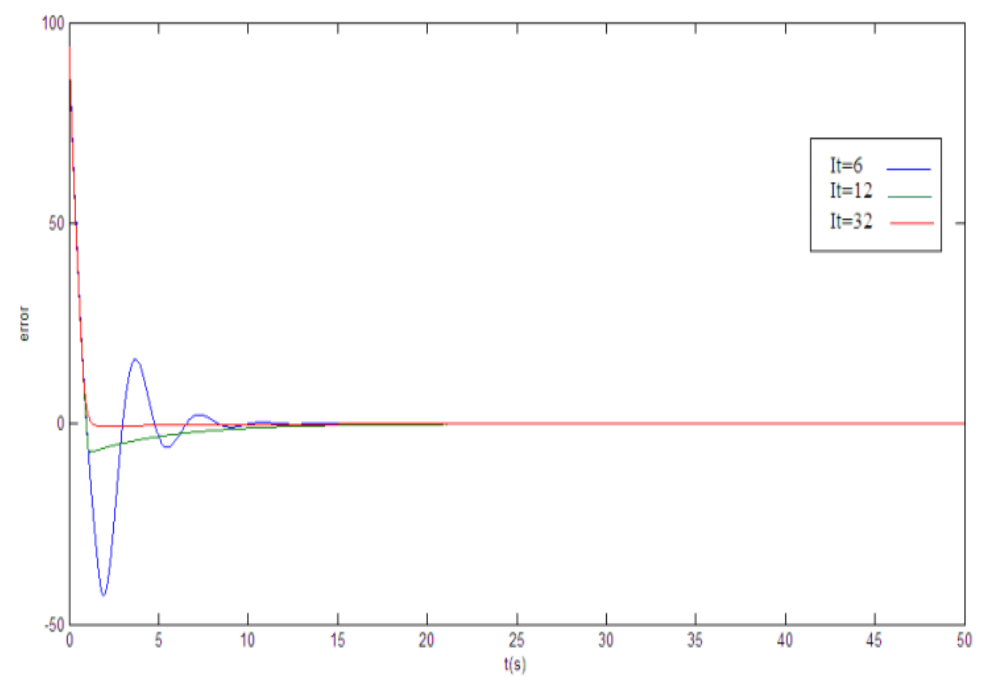

Figure 14. The (rotor speed) error of the wind turbine after designing the controller $\mathrm{B}=10$ 


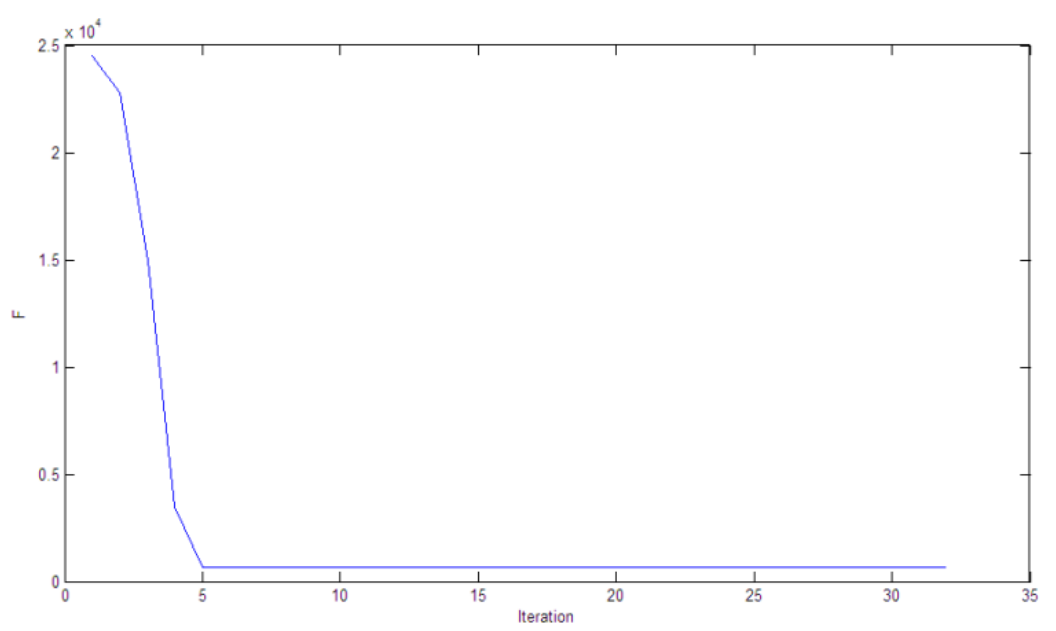

Figure 15. The objective function for $\mathrm{B}=8$

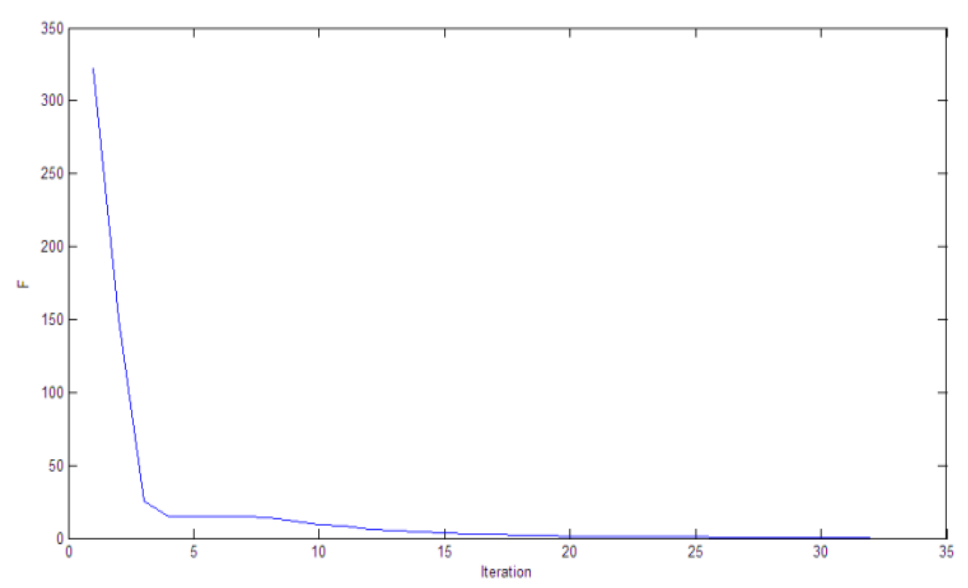

Figure 16. The objective function for $\mathrm{B}=10$

\section{CONCLUSION}

The role of coefficient adjustment is significant in two respects: First, the change in controller parameters alters the performance of system closed-loop, second, the parameters are weights or coefficients that show what proportion of these commands should be added together and then applied to the input process. In this study, particle swarm optimization (PSO) algorithm was used for the design of the PID controller parameters and results showed that in the thirtysecond repeat the desired solution have been achieved.

\section{References}

h. h. el-tamaly, a. a. e. mohammed,(2008) "modeling and simulation of photovoltaic/wind hybrid electric power system interconnected with electrical utility", 1eee conf., 12th international mepcon, pp. 645649.

the world wind energy association,(2011) "halfyear report 2011", wwea trans., germany, pp. $1-7$.

v. lesic, m. vasak, n. peric, t. wolbank, g. joksimovic,(2011) "fualt tolerant control of a blade pitch wind turbine with inverter fed generator", reee conf., international symposium on industrial electronics(1sie), vol. 1, no. 1, pp. 2097-2102, aug.

james blyth oxford dictionary of national biography,(2009) oxford univercity press, etrieved-10-09.

swedish energy agency, climate report,(2002) swidish energy agency, tech .rep.

j. g. slootweg, s. w. h. d. haan, h. polinder, w. 1. kling, (2003)“"general model for representing variable speed wind turbines in power 
system dynamics simulations", 1eee trans., power systems, vol. 18, no. 1, pp. 144-151.

g. 1. johnson, (2006)"wind energy systems", book, manhattan, ks.

f. a. abbas, m. a. abdulsada, f. r. abusief,(2011) "speed control of wind turbine by using pid controller", eng. \& tech. journal, vol. 29, no. 1, pp. 65-71.

m. hand, "variable speed wind turbine controller systematic design methodology- a comparison of non linear and linear model based designs", nrel report no. tp-500-25540, national renewable energy laboratory, july1999. 